\section{Correcting iron deficiency}

Aust Prescr 2017:40:49

http://dx.doi.org/10.18773/austprescr.2017.023

My colleagues and I recently noted that the article on correcting iron deficiency did not include up-todate information on intravenous iron replacement therapy in Australian hospitals.'

Iron polymaltose has been used for decades and in the last five years there have been additional clinical studies across several Victorian hospitals looking into the safety and rapid administration of high doses. ${ }^{2-6}$ This information was omitted from the article despite the new data on safety and adaptation of the rapid infusion protocol for iron replacement using the safe and cheaper alternative to the newer product ferric carboxymaltose.

Many tertiary centres provide medication administration infusion services, which include iron polymaltose for management of iron deficiency anaemia. Using iron polymaltose negates the inconvenience of using ferric carboxymaltose on numerous occasions for doses over $1000 \mathrm{mg}$. This is common as the average dose for iron replacement is approximately 1200-1300 mg.

Patients who would benefit from ferric carboxymaltose are those with renal or heart failure who do not require doses over $1000 \mathrm{mg}$, and patients with mild-moderate iron deficiency requiring doses of $1000 \mathrm{mg}$ or less with poor oral drug adherence or intolerance to oral supplements. These people can be treated with a single dose of ferric carboxymaltose.

Omission of this information for your readers does not provide them with a comprehensive update on current practice in the management of iron deficiency anaemia.

louri Banakh

Clinical pharmacist

Pharmacy Department

Frankston Hospital

Peninsula Health

Vic.

louri Banakh has previously received a grant provided by the Society of Hospital Pharmacists of Australia and sponsored by Sanofi.

\section{REFERENCES}

1. Baird-Gunning J, Bromley J. Correcting iron deficiency. Aust Prescr 2016;39:193-9. http://dx.doi.org/10.18773/ austprescr.2016.069

2. Garg M, Morrison G, Friedman A, Lau A, Lau D, Gibson PR. A rapid infusion protocol is safe for total dose iron polymaltose: time for change. Intern Med J 2011;41:548-54. http://dx.doi.org/10.1111/j.1445-5994.2010.02356.x

3. Tampi R, Herrmann R, Barr A, Wright M. Rapid iron infusion with iron polymaltose: further improvements may be possible. Intern Med J 2012;42:111. http://dx.doi.org/ 10.1111/j.1445-5994.2011.02635.x

4. Banakh I, Lam A, Turek M, Htet TD, Vorlander C. Rapid versus standard iron polymaltose infusions: a single centre safety study. J Pharm Pract Res 2016 Nov 16 [Epub ahead of print]. http://dx.doi.org/10.1002/jppr.1236

5. Chan PT, Corallo CE, Dooley MJ, Poole SG, Gibson PR. Safety of rapid infusion of iron polymaltose: comparative study in 300 patients. J Pharm Pract Res 2016:46:324-30. http://dx.doi.org/10.1002/jppr.1158

6. Newnham E, Ahmad I, Thornton A, Gibson PR. Safety of iron polymaltose given as a total dose iron infusion. Intern Med J 2006;36:672-4. http://dx.doi.org/10.1111/ j.1445-5994.2006.01156.x

Jonathan Baird-Gunning and Jonathan Bromley, the authors of the article, comment:

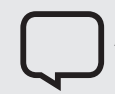
As stated in our article, we agree that iron polymaltose is the preferred preparation for hospital inpatients due to its low cost and ability to be given at doses greater than $1 \mathrm{~g}$ in a single infusion. We note the recent studies in Victoria assessing the safety of administering this preparation as a rapid infusion - 75 minutes for doses less than 1500 mg and 100 minutes for 1500-2000 mg have been proposed. This appears to have a similar safety profile to the standard slow infusion protocol. ${ }^{1}$ The potential benefit in an ambulatory setting could be for those requiring higher infusion doses, especially in rural settings where travel time needs to be considered in addition to infusion cost and nursing time. Ferric carboxymaltose requires only a 15-minute infusion, however as we highlighted the total dose cannot exceed $1 \mathrm{~g}$.

It must be stressed that the product information does not currently support the rapid protocol for iron polymaltose and clinicians would need to discuss this approach with their drug and therapeutics committees if they wish to consider these changes.

\section{REFERENCES}

1. Chan PT, Corallo CE, Dooley MJ, Poole SG, Gibson PR. Safety of rapid infusion of iron polymaltose: comparative study in 300 patients. J Pharm Pract Res 2016;46:324-30. http://dx.doi.org/10.1002/jppr.1158 